\title{
CARACTERIZAÇÃO DO PERFIL PROTEICO DO BIOFILME FORMADO "in vitro" POR S. mutans CULTIVADO SOBRE DIFERENTES CONDIÇÕES FISIOLÓGICAS
}

Charlene MEM, Elaine Machado BENELLI

A fermentação de carboidratos e produção de ácidos pelos microrganismos do biofilme dental causa redução do $\mathrm{pH}$ local favorecendo a desmineralização das superfícies dentais. Estas mudanças favorecem o crescimento de espécies como o Streptococcus mutans. O objetivo deste trabalho é verificar o perfil proteico do biofilme formado por $S$. mutans em presença de diferentes fontes de carbono e nitrogênio. $O$ biofilme foi formado em lâminas de vidro imersas em meio LMW contendo diversas fontes de carbono e nitrogênio. O perfil proteico das células foi avaliado por eletroforese (SDS-PAGE). Os resultados mostram que o $\mathrm{pH}$ final das culturas crescidas em presença de fontes de carbono ou nitrogênio foram 4,5 a 5 , ou 7 , respectivamente. $O$ perfil proteico das culturas crescidas em presença de sacarose, glucose e frutose diferem do perfil observado na presença de glucose/frutose e amônia, sugerindo que o microrganismo responde de formas diferentes dependendo da condição do meio. Os extratos proteicos das culturas crescidas em presença de sacarose/amônia e sacarose/uréia sintetizam a proteína $g l n R$ de $S$. mutans, mas não a proteína $g l n K$, sugerindo que a expressão de $g / n K$ em $S$. mutans é regulada negativamente pela proteína $g / n R$ em presença de excesso de carbono e nitrogênio.

Palavras-chave: Streptococcus mutans; placa dental; metabolismo. 